\title{
Phototherapy as an effective treatment for Majocchi's disease - Case report
}

\author{
Tapan Kumar Dhali ${ }^{1}$ \\ Mohammad Asad Haroon
}

Monica Chahar ${ }^{1}$

DOI: http://dx.doi.org/10.1590/abd1806-4841.20153067

\begin{abstract}
Pigmented purpuric dermatoses are chronic and relapsing disorders characterized by a symmetrical rash of petechial and pigmentary macules, mainly confined to the lower limbs. Purpura annularis telangiectodes of Majocchi is a less common variant of Pigmented purpuric dermatoses characterized by punctate telangiectatic macules progressing to annular, hyperpigmented patches with central clearing and infrequent atrophy. A 12year-old girl presented with asymptomatic round to oval reddish brown macules, present symmetrically over her lower and upper limbs for 3 years. Few lesions were annular in shape. Biopsy from the lesion was compatible with Pigmented purpuric dermatoses. On the basis of clinical and histopathological findings, a diagnosis of Purpura annularis telangiectodes of Majocchi was made. The patient began phototherapy thrice a week and showed excellent response.
\end{abstract}

Keywords: PUVA therapy; Phototherapy; Pigmentation disorders

\section{INTRODUCTION}

Pigmented purpuric dermatoses (PPD) are chronic and relapsing disorders characterized by a symmetrical rash of petechial and pigmentary macules, mainly confined to the lower limbs. They have traditionally been divided into five clinical entities: progressive purpuric dermatosis (Schamberg's disease), purpura annularis telanjiectoides (Majocchi's disease), pigmented purpuric lichenoid dermatosis (Gougerot-Blum), lichen aureus and eczematid-like purpura of Doucas and Kapetanakis. ${ }^{1}$ The etiologies of these conditions are unknown but histopathology indicates that a common immunopathogenetic mechanism is involved in all the subtypes. ${ }^{2}$

Purpura annularis telangiectodes of Majocchi (PATM) is a less common variant of PPD characterized by punctate telangiectatic macules, progressing to annular, hyperpigmented patches with central clearing and infrequent atrophy, mostly seen in young females. The disease entity remains an enigma and a therapeutic challenge. We report a PATM case that showed excellent response to phototherapy. ${ }^{2}$

\section{CASE REPORT}

A 12 year-old female presented with reddish brown lesions over both legs, which she had had for 3 years. The lesions started as asymptomatic round to oval reddish brown macules, present symmetrically over the ankles, progressing gradually in number, size and extent, ultimately affecting the upper limbs, too. These macules were of varying shapes, while size ranged from $0.3 \times 0.3 \mathrm{~cm}$ to $12 \times 5 \mathrm{~cm}$. Few macules showed central atrophy over the surface. On palpation, these macules were non-tender and non-blanchable, with no rise in surface temperature. Palms, soles and mucosae showed no abnormalities. Family history was negative and there was no past history of any

Received on 19.8.2013.

Approved by the Advisory Board and accepted for publication on 27.10.2013.

Work performed at the Department of Dermatology, Employees' State Insurance- Postgraduate Institute of Medical Sciences and Research (ESI- PGIMSR) Basaidarapur, New Delhi, India.

Financial Support: none

Conflict of Interests: none

Employees' State Insurance- Postgraduate Institute of Medical Sciences and Research (ESI- PGIMSR) - New Delhi, India. 
preceding infection or drug intake. Her routine examinations, including clotting profile, were normal. Antinuclear antibodies were not detected and viral hepatitis markers were negative (Figures 1 and 2).

Histopathological examination of lesion on Hematoxylin and Eosin stain revealed normal epidermis, prominent erythrocyte extravasation in the dermis and the subcutaneous tissue, along with a lympho-histiocytic infiltrate in dermis, confined mainly to periappendageal and perivascular areas. Stains for fungus and mycobacteria revealed no organism (Figure 3).

On the basis of clinical and histopathological findings, a diagnosis of PATM was made.

The patient began phototherapy (thrice weekly) with psoralen plus ultraviolet A (Derma India, Spiegel series, UVA 18, NB-UVB 18) at a dose of 1.8 $\mathrm{J} / \mathrm{cm}^{2}$. At each session, the dose was increased by $10 \%$ of the previous dose. The lesion started showing improvement at $4.0 \mathrm{~J} / \mathrm{cm}^{2}\left(10^{\text {th }}\right.$ session) and this dose was maintained till the $18^{\text {th }}$ session, after which the

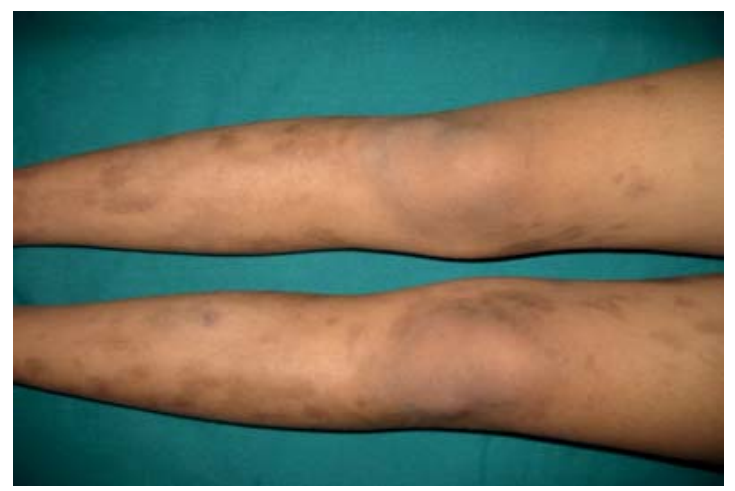

Figure 1: Multiple macules over bilateral thighs and legs (extensor aspect)

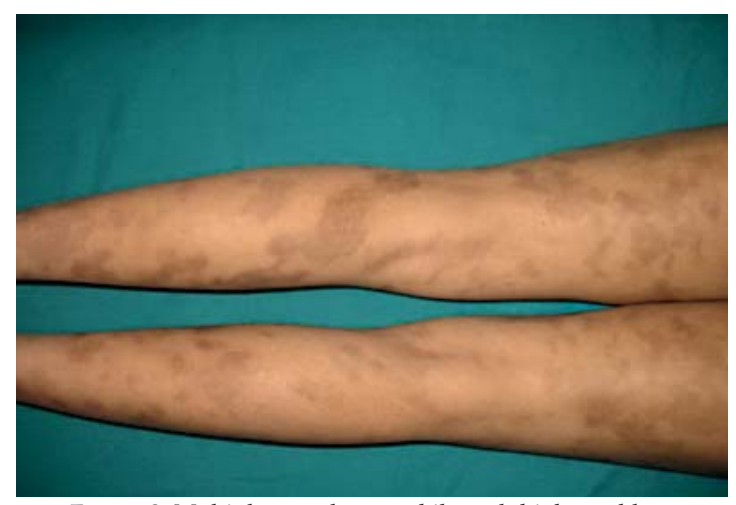

FiguRE 2: Multiple macules over bilateral thighs and legs (flexor aspect)

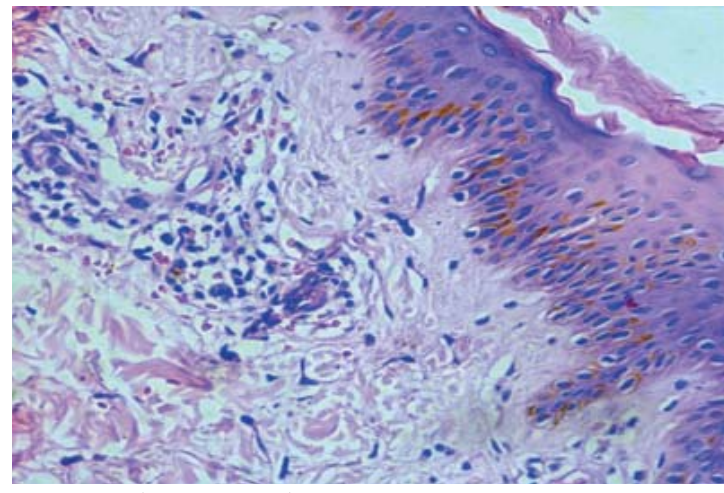

Figure 3: (H\&E staining): Prominent RBC extravasation seen in higher magnification $(400 \mathrm{X})$

patient complained of generalized itching, nausea, vomiting and abdominal pain, suggesting intolerance to PUVA (cumulative dose of $62 \mathrm{~J} / \mathrm{cm}^{2}$ ). PUVA therapy was stopped and the patient was investigated. All routine investigations including USG abdomen were normal and the patient was managed symptomatically. After 2 weeks, the patient recovered completely and Narrow Band UVB (NB-UVB) was started in place of PUVA. NB-UVB was also given in thrice weekly sessions, with a starting dose of 280 $\mathrm{mJ} / \mathrm{cm}^{2}$ and increments of $10 \%$ per session. This schedule was continued for 12 sessions, after which NB-UVB was given twice weekly without any increments for a further 12 sessions. Following a total of 24 sessions (cumulative dose of $16 \mathrm{~J} / \mathrm{cm}^{2}$ ), most of the lesions resolved completely without the occurrence of any new lesions. The patient is now on regular followup, with complete resolution of the older lesions and no recurrence after 1 year (Figures 4 and 5).

\section{DISCUSSION}

Pigmented purpuric dermatoses (PPDs) are usually chronic and persistent dermatoses. Majocchi's disease -a rare variant of PPD - is characterized by symmetrical, annular patches, including punctuate red-brown macules, with a predilection for the lower extremities. The disease affects predominantly children and young adults with female predilection. The aetiology of PPD is still unclear. While gravity and venous insufficiency are important localizing factors in many cases, various medications, contact allergy to clothing dyes and focal infection, may play a role in some patients. ${ }^{2,3}$ Burrows et al. indicated the active role of $\mathrm{T}$ cells in capillaritis. Furthermore, some authors suggest that cell-mediated immunity is a factor. Immunohistologically, Schamberg's disease reveals a perivascular infiltrate of $\mathrm{CD} 3+, \mathrm{CD} 4+$ and CD1a+ dendritic cells. ${ }^{4}$ 


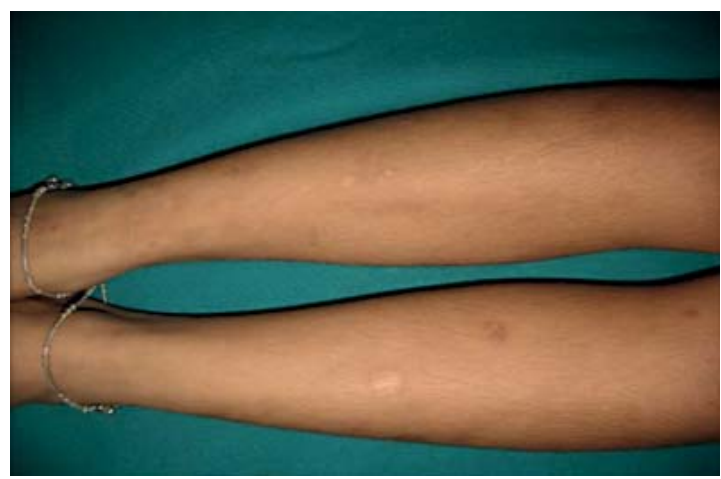

FIGURE 4: Marked improvement in macules over bilateral legs (extensor aspect)

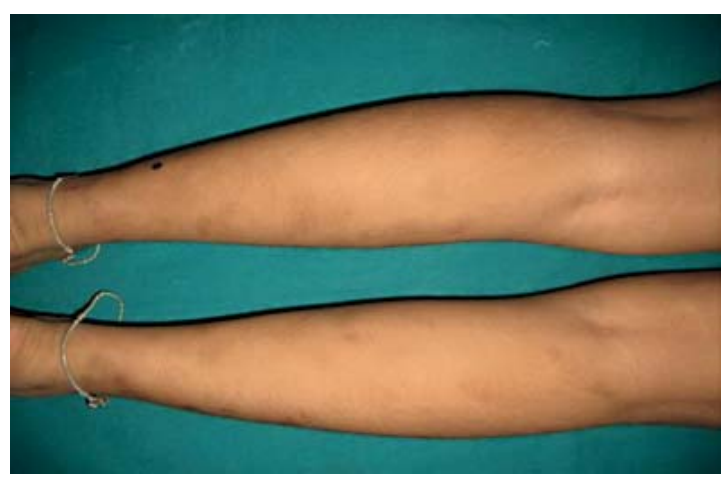

FIGURE 5: Marked resolution seen over flexor aspect of bilateral legs
Treatment of PPDs is usually difficult. Phototherapy has been reported to be effective in a small number of patients in the literature. Gudi and White were the first to report the effectiveness of NBUVB in treating a patient with Schamberg's disease. ${ }^{5} \mathrm{~A}$ total of 24 treatments were given with a cumulative dose of NB-UVB $11 \mathrm{~J} / \mathrm{cm}^{2}$. Subsequently, Lasocki and Kelly treated another Schamberg's disease patient with NB-UVB in combination with oral prednisolone in tapering doses. ${ }^{6}$ Kocaturk et al. reported a case of pigmented purpuric lichenoid dermatitis that improved markedly with 20 NB-UVB treatments, followed by another 10 maintenance sessions with a total cumulative dose of $27 \mathrm{~J} / \mathrm{cm}^{2}$.

Fathy and Abdelgaber reported six cases of PPD, including one case of Majocchi's disease, all of whom responded successfully to 24-28 NB-UVB treatment sessions which were followed by further nine treatments as maintenance therapy to avoid recurrence. ${ }^{3}$ To the best of our knowledge, this is the only prior report indicating treatment of Majocchi's purpu- ra with light therapy. Similarly, our Majocchi's purpura patient was treated successfully with phototherapy.

The proposed action mechanism of PUVA therapy in PPD is immune modulation with alteration in the activity of $\mathrm{T}$ lymphocytes and concomitant suppression of interleukin-2 production. ${ }^{8,9}$ The effectiveness of NB-UVB in PPD is probably due to its immune suppressive effect on the skin. Ozawa et al. have demonstrated that $312 \mathrm{~nm}$ ultraviolet $B$ light induces apoptosis in both epidermal and dermal T cells of psoriatic lesions. ${ }^{10}$ It is possible that NB-UVB acts similarly in PPD. We contend that phototherapy suppresses disease activity by immune suppression in the skin, leading to complete clearance of the lesions.

In conclusion, PPDs are uncommon but difficult-to-treat dermatoses. Phototherapy is an effective and safe option in treating PPDs and can be considered a first-line therapy. Further studies should be carried out to confirm the role of phototherapy in Majocchi's disease. 


\section{REFERENCES}

1. Sardana K, Sarkar R, Sehgal VN. Pigmented purpuric dermatoses: an overview. Int J Dermatol. 2004;43:482-8.

2. Hoesly FJ, Huerter CJ, Shehan JM. Purpura annularis telangiectodes of Majocchi: case report and review of the literature. Int J Dermatol. 2009;48:1129-33.

3. Fathy $\mathrm{H}$, Abdelgaber $\mathrm{S}$. Treatment of pigmented purpuric dermatoses with narrowband UVB: a report of six cases. J Eur Acad Dermatol Venereol. 2011;25:603-6.

4. Burrows NP, Jones RR. Cell adhesion molecule expression in capillaritis. J Am Acad Dermatol. 1994;31:826.

5. Gudi VS, White MI. Progressive pigmented purpura (Schamberg's disease) responding to TL01 ultraviolet B therapy. Clin Exp Dermatol. 2004;29:683-4.

6. Lasocki AL, Kelly RI. Narrowband UVB therapy as an effective treatment for Schamberg's disease. Australas J Dermatol. 2008;49:16-8.

7. Kocaturk E, Kavala M, Zindanci I, Zemheri E, Sarigul S, Sudogan S. Narrowband UVB treatment of pigmented purpuric lichenoid dermatitis (Gougerot-Blum). Photodermatol Photoimmunol Photomed. 2009;25:55-6.

8. Wong WK, Ratnam KV. A report of two cases of pigmented purpuric dermatoses treated with PUVA therapy. Acta Derm Venereol. 1991;71:68-70.

9. Krizsa J, Hunyadi J, Dobozy A. PUVA treatment of pigmented purpuric lichenoid dermatitis (Gougerot-Blum). J Am Acad Dermatol. 1992;27:778-80.

10. Ozawa M, Ferenczi K, Kikuchi T, Cardinale I, Austin LM, Coven TR, et al. 312-nanometer ultraviolet B light (narrow-band UVB) induces apoptosis of T cells within psoriatic lesions. J Exp Med. 1999;189:711-8.
MAILING ADDRESS:

Monica Chahar

Department of Dermatology,

ESI- PGIMSR, Basaidarapur

New Delhi- 110015

E-mail: chahar.monica@yahoo.com

How to cite this article: Dhali TK, Chahar M, Haroon MA. Phototherapy as an effective treatment for Majocchi's disease - Case report. An Bras Dermatol. 2015;90(1):96-9. 